\title{
Electronic communication for distance education: $A$ comparison of AUSTPAC, MINERVA, TELEMEMO and VIATEL
}

\author{
David Kember \\ Capricornia Institute of Advanced Education
}

\begin{abstract}
Distance education has at its disposal new technologies such as the telecommunications data bases. In this article a comparison of these alternatives is presented.
\end{abstract}

Distance education students are geographically separated from their lecturers so that the interactive communication, which the internal student enjoys with the lecturer, can be limited, slow, expensive and frustrating. The traditional mode of communication has been by post, centred around assignments which gave rise to the term correspondence education. Allowing for marking and internal handling, very few students would receive a reply to a posted assignment within a week and turnaround times of several weeks are not uncommon, which provides little chance for remedial feedback in a semester as short as fourteen weeks. The most popular alternative has been the telephone, which is quite expensive at day-time rates, can be frustrating when "the lecturer is never in his office" and is unable to handle larger messages like essays.

Alternative communication media are worthy of investigation since research indicates that the frequency and quality of interaction between the lecturer and student does influence the student's chances of succeeding with the course. (Rekkedal, 1973; Baath, 1980; Barker et al, 1985). 
Electronic communication between computers coupled via modems by the public telephone network is an option worth considering. The message is sent virtually instantaneously, which makes it attractive compared to post. It can handle longer communications such as essays and there is no need for the recipient of the message to be in the office to receive it. However, it is not as suitable as the phone for direct interactive conversation.

If it is accepted that electronic communication does add a further useful medium for lecturer student interaction, the potential user is then faced with choosing between several alternative services. This article discusses the costs and facilities of the recently introduced communication services: AUSTPAC, MINERVA, TELEMEMO and VIATEL.

The four services are evaluated in the context of their introduction as an electronic communication service between Capricornia Institute and its external students. The assumptions, needs, and coatings are transparently presented in some detail so that those in other institutions with different needs and situations can draw their own conclusions The facilities and pricing structures of the four services are sufficiently diverse that a conclusion reached for one institution will not necessarily apply directly to another.

The discussion may also be of relevance to organisations or businesses which have to communicate with a geographically dispersed network of clients, or members of staff. Anticipating the needs of every such organisation is out of the question but again if the services, coatings, and options are presented sufficiently transparently, the organisations should be able to superimpose their own needs on the options and draw relevant conclusions.

\section{The Communication Network}

To participate in an electronic communication system a student needs access to a telephone, computer and modem. A recent survey of Capricornia Institute external students (1) indicated that $60.7 \%$ of students either owned or had access to a computer and $12.8 \%$ of the total sample owned or had access to a modem. In considering the survey data, one needs to bear in mind that ownership of computers is expected to grow in the future as prices fall. The incidence of modems is also anticipated to increase. The availability of computer services accessible at reasonable cost via the public telephone network will increase the desire for modems which in turn should lead to price reductions. 
It is not anticipated that many students would purchase a micro and modem solely to participate in an electronic communication network for distance education, though those already possessing a micro might purchase the necessary modem. An electronic communication system would initially only be used by a limited proportion of students from their homes. This should not be seen as a distraction from its introduction as it acts as a complement to existing communication channels.

Capricornia Institute offers courses in computing and computer related areas. In an effort to make available computer facilities to students without personal access to a computer, NEC APCIII microcomputers have been placed in thirteen study centres in major population centres of Queensland. The study centres would participate in a communication network and provide access to the system for those without personal computers.

At the main campus of the institution there is a need for a number of communication nodes. Each department with external students and a number of service departments need a "mail box" and some lecturers heavily involved in external teaching, who are active computer users, would prefer and justify their individual mail box.

\section{Types of Communication}

The major types of communication the network would anticipate handling are:

1. Short messages, for example administrative enquiries, course problems, requests for extensions etc.

2. Assignments ranging from long essays down to multiple choice answers and including computer programs.

3. Students logging on to the central computer to use software which is unavailable or too large for the student's micro. It is anticipated that this type of use will not be extensive as external students will use microcomputers predominantly in a stand-alone mode.

4. Logging on to the central computer to use computer managed learning systems or databases such as library catalogues.

5. Communication between the main campus and Study Centre Liaison Officers (SCLOs) who are part-time employees responsible for student liaison, located at each study centre. 


\section{Costings}

Four services are compared: AUSTPAC, MINERVA TELEMEMO AND VIATEL. For each service the cost of sending a 2000 word essay and a 50 word message are computed. Each communication assumes an average of 8 characters per word (including spaces and punctuation). For connect times a 300 baud modem is assumed and calculated time assumes efficient downloading from a disk. In practice totally efficient downloading is not possible with AUSTPAC or AUSTPAC-based services as packets are rarely filled. Storage charges are not added to the sample costing since it is assumed that messages will be read promptly and either purged or printed out. All example coatings are for off- peak use.

The costings for each service assume that the students pay for messages they send, as they would if instead the messages had been sent by mail or phone. Should the institution decide to pay for the student's message they would have to pay the connect, volume and storage charges incurred by the students. They would not have to pay registration fees for the students, however, as each student would become a user within the institutions account hierarchy.

\section{Option 1: AUSTPAC to Central Computer}

AUSTPAC is Telecom's packet switched data communication service. AUSTPAC itself does not offer an electronic mail service. To use it for this type of communication a computer is needed at the main campus which has electronic mail software. Students then logon to the central computer via AUSTPAC and deliver messages to the relevant department or lecturer account. Replies are mailed to the student's account to be read on the next occasion that the student logs on.

Beside the electronic mail mode AUSTPAC permits students to logon and use the central computer. The therefore have access to programs which might not run on their microcomputer, CML systems and databases such as online library catalogues. AUSTPAC is the only one of the four systems which does permit use of a central computer.

\section{Cost to Student (2)}

1. "Network User Identifier ", initial registration fee of $\$ 50.00$ plus $\$ 4.00$ per month. If the Network User Group facility is not used the institution will be billed when students use the institution's AUSTPAC node. 
2. Connect charge of $\$ 4.00$ per hour plus 15 cents per call.

3. Volume charge of $\$ 1.00$ per kilosegment (up to 512,000 bits). This volume charge is discounted by $50 \%$ outside 0800 to 1800 EST Monday to Friday.

\section{Cost to Institution}

There is no cost to the institution associated with returning messages because replies are mailed to students account on the central computer. There is therefore no need to install modems at each mailbox around the campus; existing terminals in the central computer suffice.

As for the other three systems, modems would be needed for the microcomputers at any study centres and there would be charges for any messages originating from the study centres.

A major cost to the institution for using AUSTPAC is for the PAD. Charges depend on the type of terminal and the data rate. To give a feeling for the magnitude of the costs Capricornia Institute paid a one-off installation charge of $\$ 984$ and is currently paying $\$ 408$ per month for the PAD at the main campus.

The real charges for using AUSTPAC in these two examples would be more than these theoretical figures since packets would not be filled.

\section{Example Costing 1: A 2000 word essay on AUSTPAC}

Assume a 2000 word essay, with an average of 8 characters per word:= 16000 characters $=128000$ bits $=0.25$ kilosegments

Volume charge $=25$ cents peak or 13 cents off peakConnect time, assuming 300 baud modem $=12800-300=427$ seconds (or 8 minutes) Connect charge $=8 \times 6.7$ cents $/$ minute $=48$ centsplus 15 cents call charge TOTAL $=13+48+15=78$ cents

\section{Example Costing 2: A 50 word message on AUSTPAC}

A 50 word message, averaging 8 characters per word $=3200$ bitsConnect time at 300 baud $=11$ secondsConnect time cost $=6.7$ cents (time for 1 minute) +15 cents call charge

TOTAL $=2+6.7+15$ cents $=24$ cents 


\section{Option 2: MINERVA}

MINERVA is an electronic mail service, run by OTC, with comprehensive software for sending, reading, editing and storing messages.

\section{Cost to Student (3)}

1. Registration fee - nil

2. $\$ 15.00$ per connect hour or 25 cents per minute

3. A storage charge per month per group of characters dependent on volume stored.

\section{Cost to Institution}

As MINERVA messages are lodged on an OTC computer the institution would have to meet the cost of sending replies to students at the above tariff. There would be a need to install a modem at each node within the institution from which replies might be sent. The result is a potential balance between the expense of providing many modems and curtailment of the number of nodes from which replies can be made, and therefore probably the use and value of the service. Beside the need for modems, there may also be a demand for software and hardware to download some incoming messages onto the institution computer system.

\section{Example Costing 1: A 2000 word essay on MINERVA}

Connect time 8 minutes...

Cost $=8 \times 25$ cents $/$ minute $=\$ 2.00$

Example Costing 2: A 50 word message on MINERVA

Assume one minute connect time, cost $=25$ cents

The cost to the institution for hardware installation which arise for MINERVA use are also applicable to the remaining two systems which are discussed. Use of the remaining two systems oblige the institutions to pay for the replies to student messages at the rate for the system. 


\section{Option 3: TELEMEMO}

TELEMEMO is an electronic mail service run by TELECOM. The service offered appears to be virtually identical to MINERVA.

Cost to Student (4)

1. One off registration and starter kit costing $\$ 25.00$

2. Connect charge 20 cents / minute peak and 15 cents/minute off peak.

3. Volume charge of 2 cents per 1000 characters.

4. Storage charge of 1 cent per 2000 characters per day.

5. There is a minimum charge of $\$ 33.00$ per month.

\section{Example Costing 1: A 2000 word essay on TELEMEMO}

Connect charge for 8 minutes $=8 \times 15=120$ cents (off peak)Volume charge for $2000 \times 8=16000$ characters $=16 \times 2$ cents $=32$ cents

TOTAL $=120+32$ cents $=\$ 1.52$

Example Costing 2: A 50 word message on TELEMEMO

Connect charge for 1 minute $=15$ centsVolume charge for $8 \times 50=400$

characters $=2$ cents

TOTAL $=17$ cents

\section{Cost to Institution}

The costs to the institution, using TELEMEMO, for installing hardware are as for MINERVA. There would be the costs of returning messages based on the above charges. For the institution using a business account the cost of registration is $\$ 200.00$ and the minimum monthly charge of $\$ 300$.

\section{Option 4: VIATEL}

VIATEL is primarily an information database and retrieval system. Hosie (1985) has discussed potential educational uses of VIATEL. It does, however, have a message facility. The disadvantage of the facility is that messages are sent by frames limited to 960 characters, which is about a quarter of an A4 page. 
Cost to Student (5)

1. Monthly subscription fee of $\$ 2.50$

2. Connect Charge of 8 cents / minute and 5 cents / minute off peak, plus a local call fee (16 cents) per call.

3. Message fee of 5 cents / frame.

\section{Example Costing 1: A 2000 word essay on VIATEL}

Access charge $=$ local call fee $=16$ centsConnect charge for 8 minutes $=8 \mathrm{x}$ $5=40$ cents (off peak)If frame holds 960 characters (or about 120

words), then 17 frames are needed

$17 \times 5$ cents frame charge $=85$ cents

TOTAL $=16+40+85$ cents $=\$ 1.51$

\section{Cost to institution}

The institution would again be liable for the cost of installing modems and replying to messages at the above rates. There is a monthly subscription fee of $\$ 12.50$ for a service provider.

Example Costing 2: A 50 word message on VIATEL

Call fee of 16 cents 1 minute connect time $=5$ cents 1 message frame $=5$ cents

TOTAL $=16+5+5=26$ cents

\section{Discussion}

\section{Facilities}

Of the services compared, MINERVA and TELEMEMO are primarily electronic mail services so the software is designed for that use. The two services offer very similar facilities. Incoming messages are indexed, scanned, read, filed or purged. There are comprehensive editing facilities for composing messages prior to dispatch. Alternatively messages can be composed and stored on your own wordprocessor and batch delivered. 
Mail box systems and bulletin boards can be established within organisations. Comprehensive documentation on these facilities are supplied to users.

On the other hand AUSTPAC is purely a service for transmitting packet switched data from point to point. It offers none of the electronic mail facilities of MINERVA or TELEMEMO. However through AUSTPAC external students can logon to the institution's central computer on its main campus. Software on that computer can provide the services necessary for electronic mail. Such software could already be in place and may be used for an existing electronic mail service around the campus.

The central computer can service other facilities not provided by the electronic mail services because the student can use any program on the computer. If extensive use of a program is needed it would normally be cheaper for a student to buy the program and run it on the micro in stand alone mode, rather than $\log$ on to the central computer for lengthy periods. For example, a student learning programming who owned a micro would usually be better off acquiring the appropriate compiler than using the main computer. Similarly use of applications software can best be taught if the student purchases educational versions of the appropriate software.

Some programs, however, will be either too large, too expensive or unavailable for the student's micro. Access to large databases, especially library catalogues, could be particularly advantageous to external students.

VIATEL is primarily a public access database. The function for sending and receiving messages appears to be provided mainly so that users can respond to information on the database. For use purely as an electronic mail service it is not as convenient as either of the services expressly provided for that purpose, particularly because of the need to break messages into short frames. So unless distance education institutions can see particular benefits to the public database role of VIATEL, there would seem to be little reason to use it for electronic mail as it is comparable in cost to services provided expressly for that purpose.

\section{Cost}

Comparison of overall coatings for an institution is complicated by the diverse pricing structures and the different types of cost involved for adopting the various systems. To use AUSTPAC, the heavy initial charge 
and monthly rental for the PAD has to be paid. The initial cost of installing the PAD would be offset by the need to install modems at communication centres around the institution. To offset against the recurrent PAD rental is the absence of cost for reading and replying to student messages because the institutions central computer is used for storing message traffic.

The balance on recurrent costs depends on the volume of message traffic. A low volume of messages would favour MINERVA. The breakeven point depends on the type of PAD installed, the length of messages and the frequency with which messages are checked.

Use of AUSTPAC implies the need for a central computer and electronic mail software. The cost of the computer must be taken into account and if the electronic mail software had the facilities of TELEMEMO and MINERVA software it would not be cheap.

In comparing the costs of MINERVA and TELEMEMO minimum monthly charge of $\$ 33$ for an individual account could act as a disincentive to opening an account. Even allowing for a reasonable increase on current student to institution communication, it is difficult to see most students sending \$33 worth of messages a month to the institution. In some months there could be no messages at all. It is therefore difficult to justify a student opening a TELEMEMO account unless there are other anticipated uses. In time the service may grow to be an alternative to TELEX which could provide alternative uses but the fledgling service has to make considerable advances to reach that status.

In view of the comparable costs of sending messages by MINERVA or TELEMEMO and the similarity of services, MINERVA could be preferred by the low volume user as it had no minimum monthly charge.

In comparing AUSTPAC and MINERVA from the student viewpoint, there is again a balance depending on usage. The monthly $\$ 4$ Network User Identifier fee for AUSTPAC has to be balanced against the lower message charges. A very low user would find MINERVA cheaper, but it would not take many messages to balance the monthly Network User Identifier fee. The initial $\$ 50$ registration fee for Network User Identifier could act as a barrier to some students using the service. If it is added to the cost of purchasing a modem the initial outlay for access to the system of not inconsiderable. 
Overall

If an institution does not have a central computer with electronic mail software and the capacity to handle electronic communication traffic, MINERVA would seem to be the preferred option. For those which do have this facility the choice seems to be between AUSTPAC and MINERVA.

AUSTPAC offers extra overall facilities in online computing and access to databases on the central computer. The institution would have to configure its electronic mail software for the convenience of the external user, essentially to provide the facilities which MINERVA and TELEMEMO offer. However, in setting up such a mail service for AUSTPAC there is the possibility of interfacing the external mail network with an internal electronic mail service and with software such as student record, assignment recording or CML systems. For AUSTPAC use there is also the initial expense of the PAD installation cost. However unless an institution is to restrict itself to one or two message nodes on the campus, which negates some of the advantages of electronic communication, the initial AUSTPAC charges will be more than offset by the need to install modems around the campus if MINERVA is used.

As AUSTPAC recurrent charges are also lower with a high message volume this could be the preferred option for a larger institution with a well established central computer system and the programming capacity to implement integrated systems. Smaller institutions or those with few external students might find MINERVA an attractive alternative. It provides an up- and- running system with no registration fees. With low usage to a limited number of nodes or mail boxes on the main campus, it would be a good option for those who desire an exploratory testing of the waters. 


\section{Summary Table}

\begin{tabular}{|c|c|c|c|c|}
\hline Item & AUSTPAC & MINERVA & TELEMEMO & VIATEL \\
\hline $\begin{array}{l}\text { Student } \\
\text { registration } \\
\text { per month }\end{array}$ & $\$ 50+\$ 4$ & - & $\$ 25$ & $\$ 2.50$ \\
\hline $\begin{array}{l}\text { Connect } \\
\text { charge per } \\
\text { minute }\end{array}$ & $15 c+6.7 c$ & $25 c$ & $15 c$ & $16 c+5 c$ \\
\hline $\begin{array}{l}\text { Volume } \\
\text { charge }\end{array}$ & $\begin{array}{c}\$ 1 / \\
\text { kilosegment }\end{array}$ & - & $\begin{array}{c}2 c / \\
1000 \text { char }\end{array}$ & $\begin{array}{l}5 c / \\
\text { frame }\end{array}$ \\
\hline Storage charge & - & Yes & Yes & Yes \\
\hline $\begin{array}{l}\text { Minimum } \\
\text { monthly } \\
\text { charge }\end{array}$ & - & - & $\$ 33$ & - \\
\hline $\begin{array}{c}\text { Cost } 2000 \\
\text { words }\end{array}$ & $76 c$ & $200 c$ & $152 c$ & 151c \\
\hline Cost 50 words & $24 c$ & $25 c$ & $17 \mathrm{c}$ & $26 c$ \\
\hline $\begin{array}{l}\text { Electronic mail } \\
\text { software }\end{array}$ & - & Yes & Yes & $?$ \\
\hline $\begin{array}{l}\text { Log on to } \\
\text { computer }\end{array}$ & Yes & - & - & - \\
\hline $\begin{array}{c}\text { Information } \\
\text { database }\end{array}$ & - & - & - & Yes \\
\hline
\end{tabular}

\section{Reference Notes}

1. Recently completed survey of Capricornia Institute external students by Kember and Dekkers. Results are not yet published.

2. Prices from Telecom AUSTPAC price list dated February 1985.

3. Prices from MINERVA International Communications Service Tariff Schedule, effective from 1st December 1984.

4. Prices from Telecom TELEMEMO Tariffs as at 1st July 1985.

5. Prices from Telecom VIATEL Price List issued April 1985. 


\section{References}

Baath, J. A. (1980). Postal Two-Way Communication in Correspondence Education. Malmo: Liberhermods.

Barker, L.J., Taylor, J.C., White, V.J., Gillard, G., Kaufman, D., Khan, A.N., and Mezger, R. (1985). Student Persistence in Distance Education: A Cross Cultural Multi-Institutional Perspective. Paper presented at the 13th World Conference of the International Council for Distance Education, Melbourne, August, 1985.

Hosie, P. (1985). Promises, promises: Viatel and education. Australian Journal of Educational Technology, 1(1) 39-46. http:/ / www.ascilite.org.au/ ajet/ajet1/hosie.html

Rekkedal, T. (1973). The Written Assignments in Correspondence Education Effects of Reducing Tum-around Time: An Experimental Study. Oslo: NKIskolen Undervisningssentrum.

Please cite as: Kember, D. (1986). Electronic communication for distance education: A comparison of AUSTPAC, MINERVA, TELEMEMO and VIATEL. Australian Journal of Educational Technology, 2(1), 43-55. http: / / www.ascilite.org.au/ajet/ajet2/ kember.html 